\title{
PICTORIAL REVIEW
}

\section{Neuroimaging findings in sickle cell disease}

\author{
'S C THUST, MD, FRCR, 'C BURKE, MRCS, FRCR and ${ }^{1,2}$ A SIDDIQUI, MD, FRCR \\ 'St Thomas Hospital, Guy's and St Thomas' Hospitals NHS Foundation Trust, Radiology Department, London, UK \\ ${ }^{2}$ King College Hospital Foundation Trust, London, UK \\ Address correspondence to: Dr Stefanie Catherine Thust \\ E-mail: steffi.thust@yahoo.co.uk
}

\begin{abstract}
At least $25 \%$ of individuals with sickle cell disease will have a neurological complication over their lifetime, often as early as in childhood. Neuroradiological findings in patients with sickle cell disease are common and include acute territorial infarction, silent ischaemia and intracranial haemorrhage. Imaging abnormalities are typically, but not always, manifestations of the underlying vasculopathy. Coexisting acute and chronic pathology may pose challenges to interpretation.
\end{abstract}

\section{BACKGROUND}

Sickle cell disease (SCD) is the most common serious genetic disorder in England occurring in $>1$ in 2000 live births. It affects descendants of Afro-Caribbean heritage, but also other ethnic groups, for example, those from Mediterranean countries, the Middle East and India. ${ }^{1-3}$ In SCD, the formation of abnormal haemoglobin impairs the ability of erythrocytes to pass through blood vessels, particularly those of smaller calibre. The normal haemoglobin molecule consists of four protein chains, namely two alpha $(\mathrm{HbA})$ and two beta $(\mathrm{HbB})$ globin chains. In SCD, a point mutation on the short arm of chromosome 11 results in the production of an abnormal beta chain (HbS), in which glutamic acid is replaced by valine. In the homozygous individual, both chromosomes contain the sickle cell mutation coding for an abnormal beta chain (HbSS), per definition leading to classic sickle cell anaemia (SCA) and typically a more severe clinical course. Classic SCA and other symptomatic disease variants, in which one HbS beta chain combines with an abnormal beta chain of a different mutation (e.g. HbS-haemoglobin C or HbS-thalassaemia) are summarized under the term SCD. The heterozygous variant of the condition, in which one normal and one abnormal beta chain are produced, is termed sickle cell trait and usually results in a milder phenotype. Under certain conditions, especially deoxygenation, $\mathrm{HbS}$ forms aggregates with other haemoglobin molecules causing red blood cells to change into a rigid sickle shape. With reoxygenation, the polymerization resolves and blood cells revert to a normal shape. Sickling may also be precipitated by other factors, for example, infection, dehydration or cold. Sickled erythrocytes no longer smoothly pass through vessels and adhere more easily to the endothelium. This results in vascular congestion, occlusion and ischaemia, which eventually progresses to chronic vasculopathy and infarction. ${ }^{4,5}$ Repeated or prolonged sickling causes red cell death in the form of haemolytic anaemia.

\section{NEUROVASCULAR SICKLE CELL DISEASE}

Neurological manifestations of SCD are common and include symptomatic infarction, silent ischaemia and intracranial haemorrhage. At least $25 \%$ of patients with SCD will have a neurological complication over their lifetime, which may occur in early childhood. ${ }^{4}$ The yearly first stroke risk in young homozygous children has been quoted around $0.5 \%{ }^{6}$ According to the Cooperative Study of SCD, the prevalence of abnormalities such as infarction, silent ischaemia and atrophy in children under 10 years is around $22 \%$. A few other studies quote even higher numbers (up to 44\%), with approximately $55 \%$ showing vasculopathy on MR angiography (MRA). ${ }^{7-9}$ Although the vast majority of patients with SCD present with vascular complications, differential diagnoses for suspected intracranial pathology should be considered, particularly in view of the increased susceptibility of patients with SCD to infection. Bone infarction, osteomyelitis and altered marrow signal due to extramedullary haematopoiesis may be observed on neuroimaging. The treatment of SCD can also result in radiological abnormalities.

\section{VASCULOPATHY}

This is the hallmark feature of the disease and the underlying cause for many of its radiological manifestations. 
Vascular abnormalities may already be evident in early childhood. Sickle cell vasculopathy can involve both large and small vessels, although typically the terminal internal carotid artery (ICA), proximal anterior cerebral artery (ACA) and middle cerebral artery (MCA) are affected leading to stenosis. Over time and with progressive occlusion of the main intracranial arteries, a so called "Moya Moya" (Japanese: puff of smoke) appearance is seen, which is characterized by the formation of numerous tiny collaterals. The exact cause of vessel narrowing remains unclear but is thought to be mediated by endothelial injury with adhesion of abnormal cellular elements, which eventually results in damage of the muscularis. Pathologically, this has been shown to correspond to a non-inflammatory intimal hyperplasia, with or without thrombosis. ${ }^{10}$ Although the damage of the vessel wall primarily results in luminal narrowing, this process may also play a role in aneurysm formation. Vasculopathy of the main intracranial arteries may result in compensatory dilatation of pial vessels, which can manifest itself on fluid-attenuated inversion-recovery imaging as a characteristic "ivy sign". ${ }^{11}$ In severe vasculopathy, surgical revascularization procedures have shown clinical benefit. ${ }^{12}$ These include direct anastomosis (usually superior temporal artery to a cortical MCA branch) and indirect techniques, such as pial synangiosis and encephalo-duroarteriosynagiosis, which involve the transfer of a scalp vessel onto the brain surface (Figure 1).

\section{TERRITORIAL INFARCTION}

Intracranial large artery infarction is the most commonly recognized stroke syndrome in children with SCD. ${ }^{13}$ These strokes are usually, but not always, associated with intracranial vasculopathy. ${ }^{14}$ Overt strokes are mostly seen in the anterior circulation and are commonly associated with occlusion or stenosis

Figure 1. (a) Digital subtraction angiography (DSA) lateral views of selective internal carotid artery (ICA) injection demonstrating stenosis of the terminal ICA with loss of middle cerebral artery filling on the early-phase image. The late-phase image shows progressive filling of ophthalmic, middle and posterior circulation leptomeningeal collaterals with a Moya Moya appearance. (b) MRI of a different patient with Moya Moya syndrome. Note the tortuous "net-like" vessels in the cerebrospinal fluid spaces and basal ganglia (thin arrows). MR angiography (MRA) image showing occlusion of the right ICA with extensive collaterals and narrowing of the left ICA with fewer collaterals. Small mature basal ganglia infarcts (block arrows) are present. (c) Fluid-attenuated inversion-recovery images demonstrating the "ivy sign" and its resolution following pial revascularization surgery in a sickle cell patient with severe Moya Moya syndrome. Chronic white matter signal changes are present in keeping with watershed ischaemia. (d) Evolution of vasculopathy on MRA and DSA with progressive right middle cerebral artery stenosis and collateral formation over time.

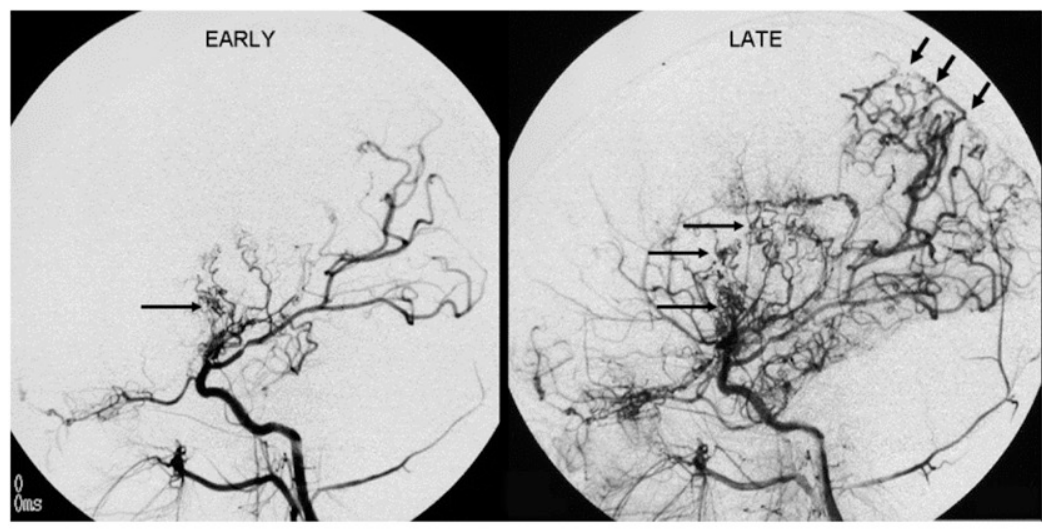

(a)

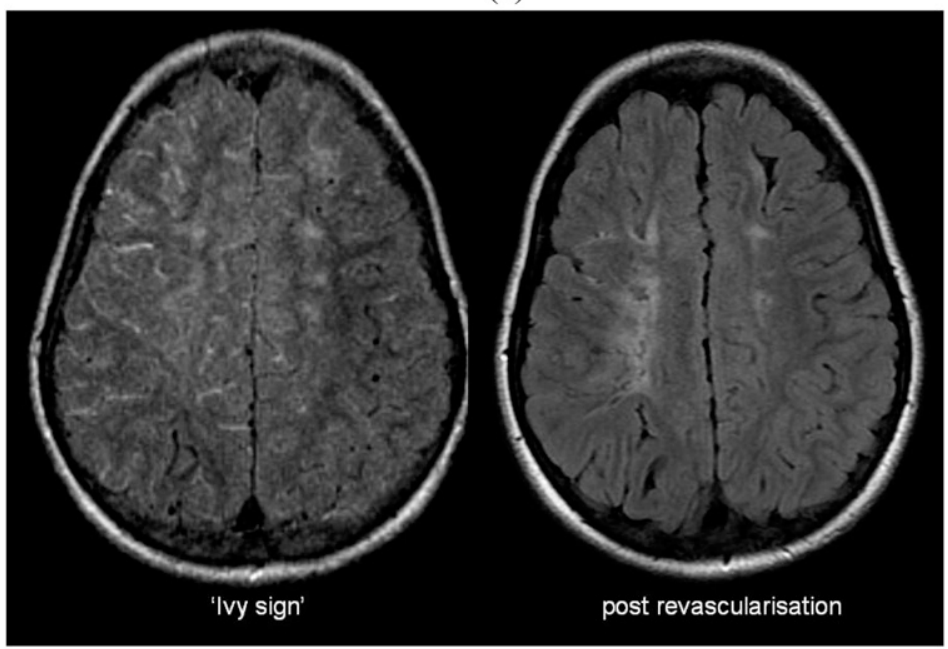

(c)

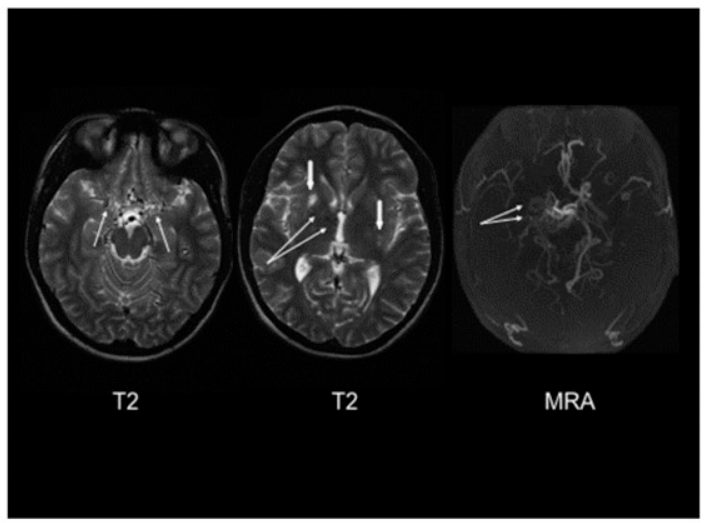

(b)

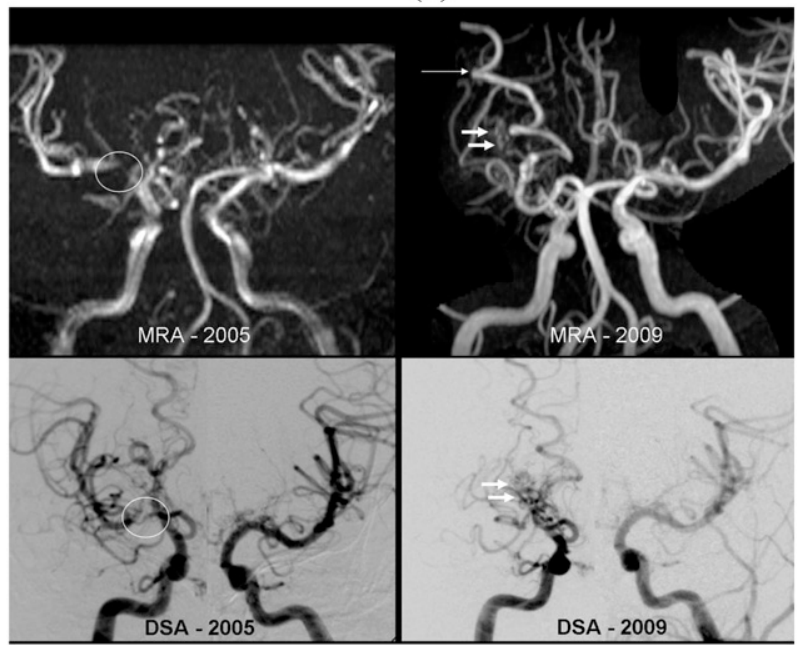

(d) 
Figure 2. (a) Unenhanced CT showing subtle loss of grey-white differentiation in the right middle cerebral artery (MCA) territory in a child with sickle cell disease presenting with left hemiparesis (Day 1). A subsequent CT reveals a clearly defined large MCA territory infarct with substantial mass effect and midline shift (Day 2). A $T_{2}$ weighted MR image 2 years later demonstrates established encephalomalacia in the area of previous infarction. Note the right frontal and parietal skull defects due to previous decompression surgery. (b) Axial time-of-flight (TOF) MR angiography and maximum intensity projection (MIP) demonstrating marked narrowing of the terminal right internal carotid artery (arrow). MRA, MR angiography.

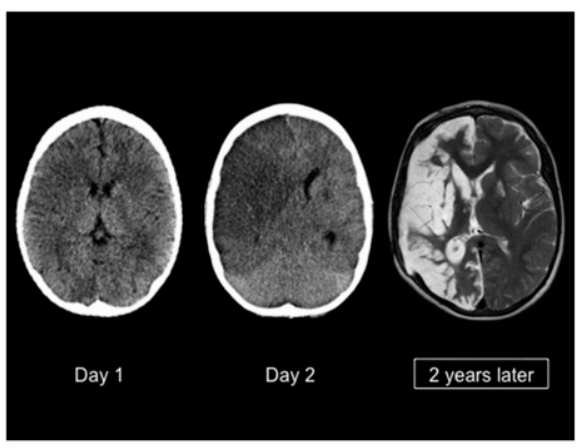

(a)

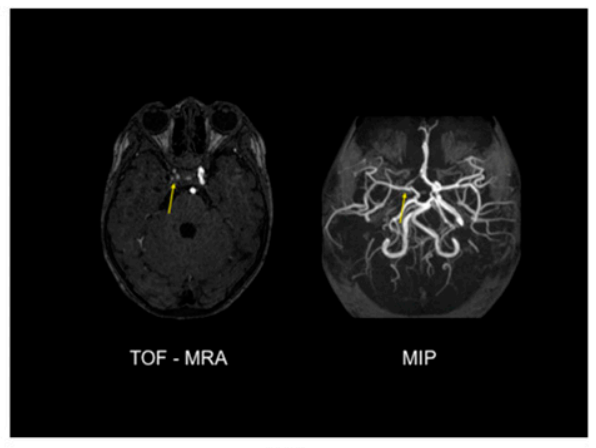

(b) of the distal ICA and/or proximal MCA. ${ }^{15,16}$ The effects of occlusion depend on the speed of occlusion and the completeness of the Circle of Willis as a source of collateral circulation. Smaller infarcts may be due to distal emboli or local stasis/thrombosis. There may be considerable variation in the territorial supply between individuals (Figure 2).

\section{SILENT CEREBRAL ISCHAEMIA}

The term silent cerebral ischaemia (SCI) is used when there are no presenting symptoms to correlate with an objective imaging abnormality, such as arterial stenosis or infarction. ${ }^{17}$ SCI typically occurs at the ("watershed") border zones of vascular territories, which are supplied by smaller endarterial branches and therefore vulnerable to ischaemia. The latter may be caused by a proximal stenosis, as is typically the case in SCD, or by generalized reduction in cerebral perfusion, e.g. in systemic hypotension. A distinction can be made between cortical watershed zones, where vascular territories border on each other, and deep watershed zones, for example, between lenticulostriate perforators and deep penetrating cortical branches of the MCA or between deep white matter branches of the ACA and MCA.

In SCA, SCI occurs in up to $27 \%$ of children before their 6 th and $37 \%$ by their 14 th birthdays. ${ }^{18}$ Ischaemia can present as subtle or overt neuropsychological deterioration or an impaired cognitive function. ${ }^{1,19-21}$ Recently, it has been shown that ischaemia may be detectable in the acute stage on diffusionweighted imaging (DWI) in patients presenting with covert/ subtle neurological symptoms and that the potential for symptomatic infarction in this group was 14 times more than those without silent infarcts. ${ }^{22,23}$ Basal ganglia infarcts may occur owing to extension of intimal hyperplasia from the terminal ICA or M1 segment of the MCA. In children with homozygous SCD, transcranial Doppler ultrasound (TCD) now forms part of the national standard in screening for asymptomatic vasculopathy. ${ }^{1}$ Silent infarcts in combination with elevated TCD velocities must prompt the initiation of preventative treatment in order to reduce the risk of subsequent stroke (Figure 3). ${ }^{24}$

Figure 3. (a) $T_{2}$ and fluid-attenuated inversion-recovery (FLAIR) images demonstrating increased signal involving the cortex and white matter of the right parietal lobe and in the watershed zones of both frontal lobes. Corresponding diffusion-weighted imaging (DWI) image and apparent diffusion coefficient (ADC) map showing restricted diffusion in the right parietal lobe abnormality indicating an acute infarct. The frontal lobe changes represent chronic watershed infarction. (b) $T_{2}$ weighted images at presentation and 2 years later demonstrating progressive silent ischaemia, most marked in the left frontal lobe.

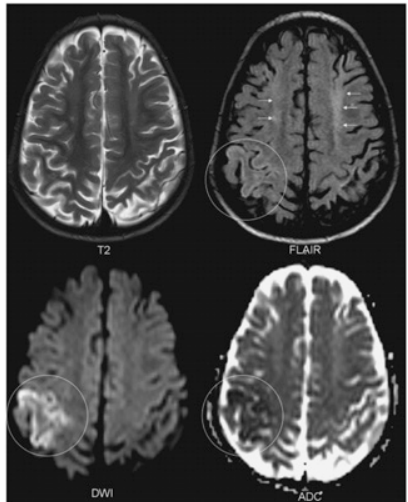

(a)

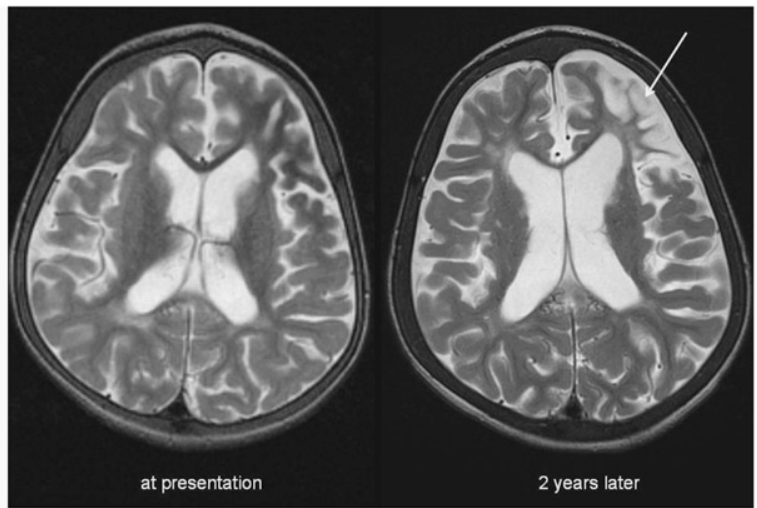

(b) 
Figure 4. Non-enhanced CT (NECT) showing widespread subarachnoid haemorrhage in the basal cisterns and cerebral sulcal spaces. There is also bilateral anterior cerebral artery infarction. Volume-rendered image demonstrates an anterior communicating artery aneurysm. CTA, CT angiography.

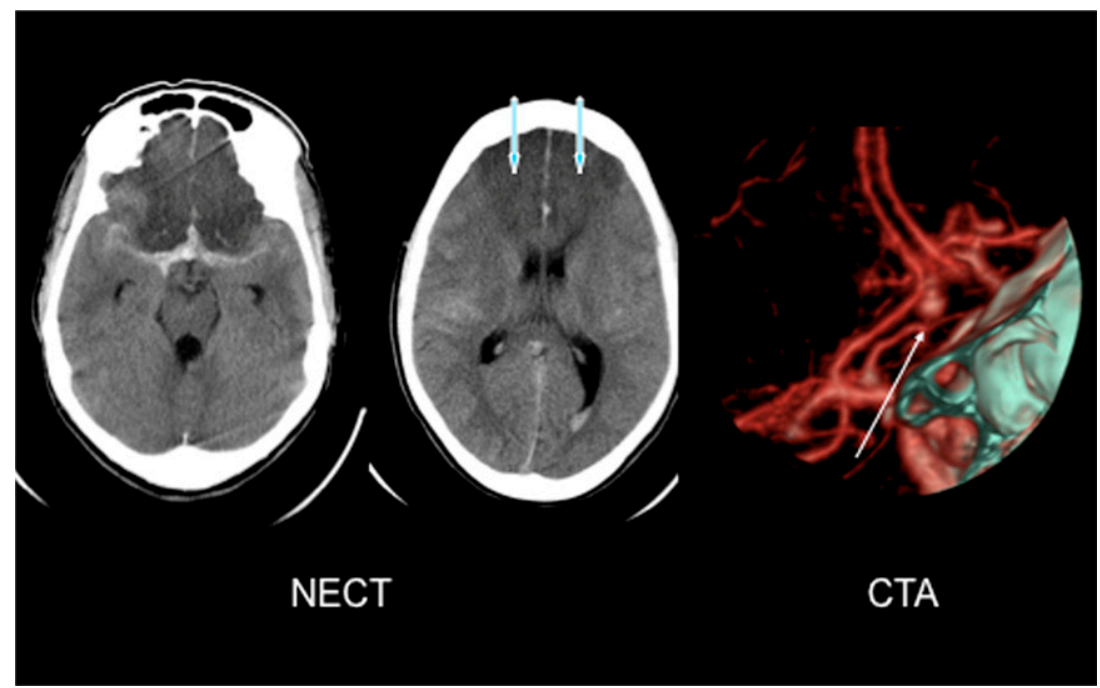

\section{INTRACRANIAL HAEMORRHAGE}

This is a rare but significant complication of the disease. Bleeding may be parenchymal due to haemorrhagic transformation of ischaemic brain or occur in the subarachnoid or intraventricular compartments. Intraventricular haemorrhage is usually encountered in older patients with Moya Moya vasculopathy. Once the diagnosis is confirmed, usually on an unenhanced CT, the cause of haemorrhage should be ascertained. Whilst the commonest cause is aneurysmal rupture, haemorrhage may also be related to rupture of friable collateral vessels that are seen in these patients. Sickle cell vasculopathy is associated with an increased risk of intracranial aneurysm formation; this is more common in adults than in children. ${ }^{13}$ Aneurysms are multiple in the majority (57\%) of patients with SCD and more often originate from the posterior circulation $(30 \%)$ than that in the normal population $(5-14 \%)$ (Figure 4$).{ }^{25}$

\section{OTHER INTRACRANIAL ABNORMALITIES IN SICKLE CELL DISEASE}

Posterior reversible encephalopathy syndrome (PRES) represents a less common complication of SCD. PRES typically manifests as vasogenic oedema with a predilection for parieto-occipital white matter, but other brain areas such as the superior frontal lobes and grey matter may be involved. Occasionally, cytotoxic oedema may also be seen. PRES in SCD has been reported in association with acute chest crisis, steroid use and overtransfusion. ${ }^{26}$ In a recent cohort of 80 children with SCD, who presented with acute neurological symptoms, $10 \%$ demonstrated appearances consistent with PRES on neuroimaging. ${ }^{27}$ In this study, PRES was associated with systemic hypertension and increased mortality, but interestingly not with pre-existing brain infarcts or intracranial vasculopathy. PRES has also been reported following allogenous bone marrow transplantation (ABMT) to treat severe SCD, whereby myeloablative neurotoxicity has been postulated as a mechanism. ${ }^{28,29}$ A further possible complication of ABMT is graft-versus-host disease, which may present as cerebrovascular disease, demyelination or immune-mediated encephalitis. ${ }^{30}$
Figure 5. A patient with chest crisis, new onset of headache and seizure. Initial MRI [fluid-attenuated inversion-recovery (FLAIR)] showing typical posterior cortical-subcortical hyperintensity (without diffusion restriction-diffusion-weighted imaging images not shown) consistent with posterior reversible encephalopathy syndrome. MR angiography (MRA) shows multifocal beading of the medium-sized arteries posteriorly (arrows), corresponding to the FLAIR changes. Follow-up images demonstrate resolution of both $M R I$ and MRA changes. Note the generalized low signal from the calvarial marrow, consistent with extramedullary haematopoiesis.

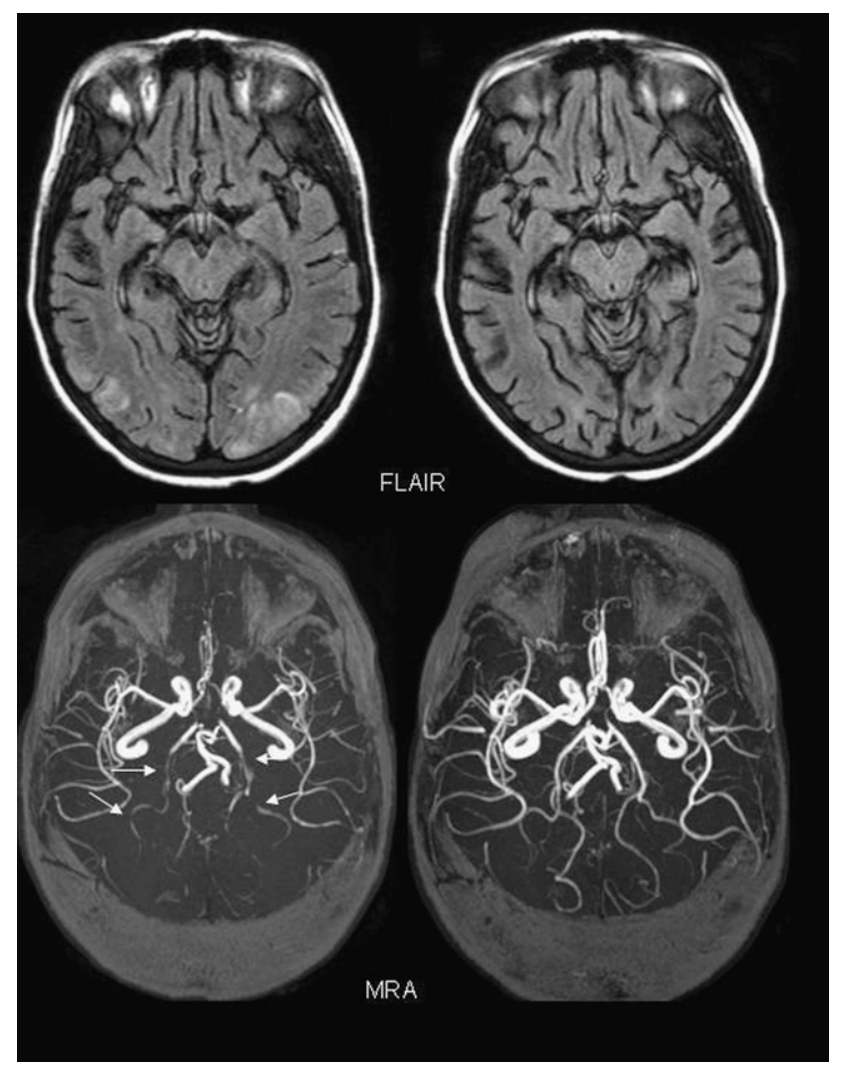


Figure 6. Sharply demarcated areas of signal abnormality in the calvarial bone marrow on both sides (long arrows) indicating bone infarcts. Associated bilateral spontaneous acute extradural haematomas (short arrows) are present (with evacuation on the right prior to MRI). DWI, diffusion-weighted imaging.

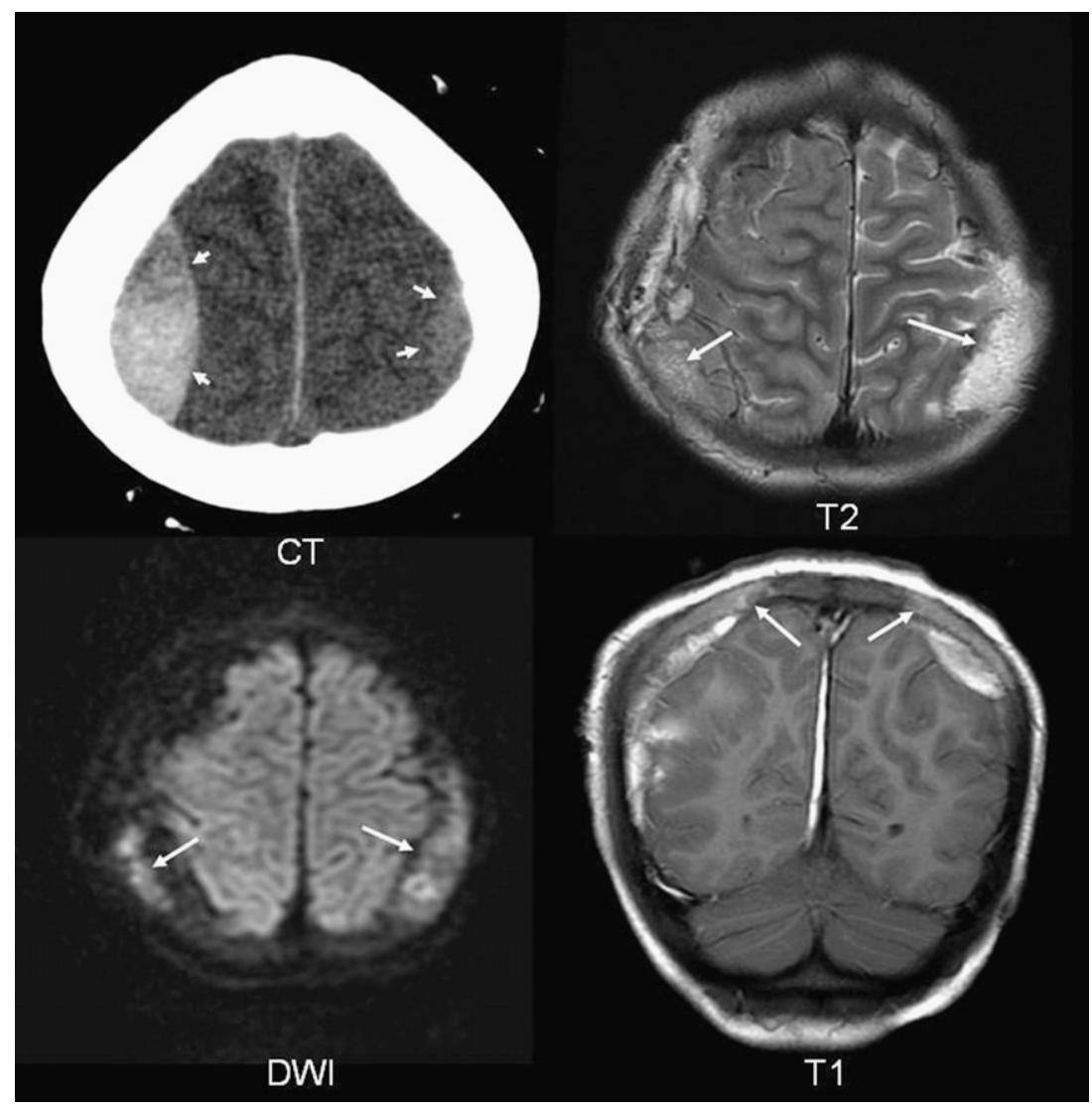

Cerebral fat embolism secondary to breakdown of infarcted bone is a rare but feared complication of SCD. This may manifest itself on MRI as multiple small foci of diffusion restriction ("starfield pattern"). ${ }^{31}$ The value of susceptibility-weighted imaging in identifying fat emboli has recently been demonstrated. ${ }^{32,33}$ Calvarial bone infarction is another uncommon complication of SCD in patients presenting with headache or orbital swelling, with imaging demonstrating bone infarction, spontaneous extradural haemorrhage or subperiosteal haemorrhage (Figures 5 and 6$).^{34}$

\section{IMAGING TECHNIQUES}

Transcranial Doppler ultrasound screening

TCD is now an integral part of the UK national standard protocol for annual screening from the age of 2 years. ${ }^{1,35}$ TCD measurements are obtained for the ACA and MCA, whereby normal velocity is defined as $<170 \mathrm{~cm} \mathrm{~s}^{-1}$. Measurements from 170 to $200 \mathrm{~cm} \mathrm{~s}^{-1}$ are classed as "conditional" and $>200 \mathrm{~cm} \mathrm{~s}^{-1}$ as abnormal. Abnormal arterial TCD velocities in children are strongly associated with vasculopathy and increased stroke risk. ${ }^{36}$ The Stroke Prevention Trial in Sickle Cell Anaemia (STOP) demonstrated a $90 \%$ reduction in stroke risk for patients receiving regular blood transfusions to decrease TCD velocities. ${ }^{13,37}$ The followup STOP2 trial, which evaluated patients in whom transfusions had been stopped and the stroke with transfusions changing to hydroxyurea trial, in which patients received hydroxyurea instead of transfusions were both halted owing to overwhelming evidence for the benefit of regular blood transfusions. ${ }^{2,38}$ It has recently been suggested that very low $\left(<70 \mathrm{~cm} \mathrm{~s}^{-1}\right)$ TCD velocities may also be abnormal and associated with an increased number of cerebral insults. ${ }^{39}$

\section{Cross-sectional imaging}

CT is readily accessible for emergency imaging and remains particularly valuable in suspected intracranial haemorrhage, whereas MRI including DWI has increased sensitivity and specificity in identifying acute stroke and chronic ischaemia. CT angiography (CTA) and time-of-flight MRA (TOF-MRA) are both useful in the assessment of cerebrovascular disease. In certain situations, CTA may be technically superior, for example, in slow flow, which may cause a stenosis to be overestimated by MRA. In TOF imaging, dephasing of spins may cause signal loss where vessels bifurcate, such as the internal carotid termination, which are unfortunately the sites of disease in SCD. Ways to overcome this problem include reducing the echo time to the lowest possible $(<5 \mathrm{~ms})$, employing a higher matrix, acquiring thinner slices or performing a contrast-enhanced MRA.

\section{Advanced imaging}

Perfusion MRI evaluates haemodynamic parameters, such as cerebral blood flow and volume and can be performed with or without intravenous (i.v.) gadolinium. Perfusion MRI shows 
Figure 7. (a) Transcranial Doppler ultrasound image showing absent flow in the right middle cerebral artery (MCA), which is proximally occluded on the corresponding maximum intensity projection MR angiography image. Normal velocity $\left(<170 \mathrm{~cm} \mathrm{~s}{ }^{-1}\right)$ is seen within left MCA. (b) Fluid-attenuated inversion-recovery (FLAIR) and continuous arterial spin labelling (ASL) images demonstrating different patterns of established white matter watershed ischaemia (arrows) and reduced blood flow in two patients. CBF, cerebral blood flow.

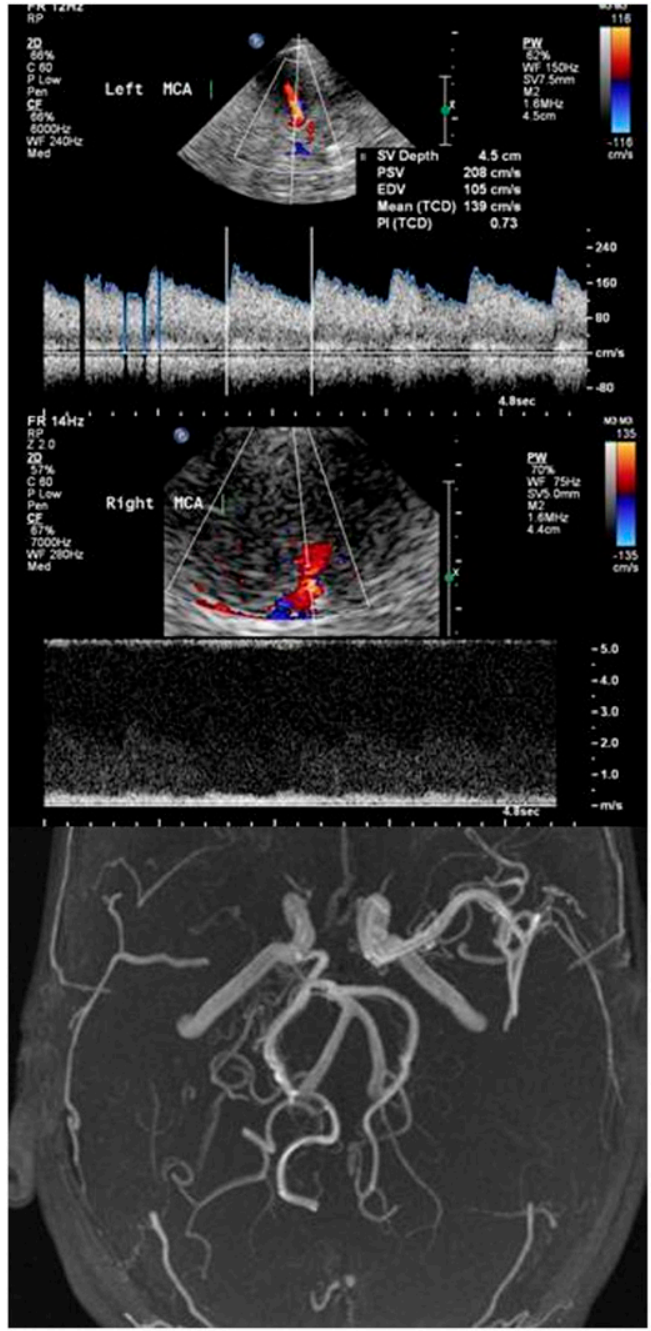

(a)

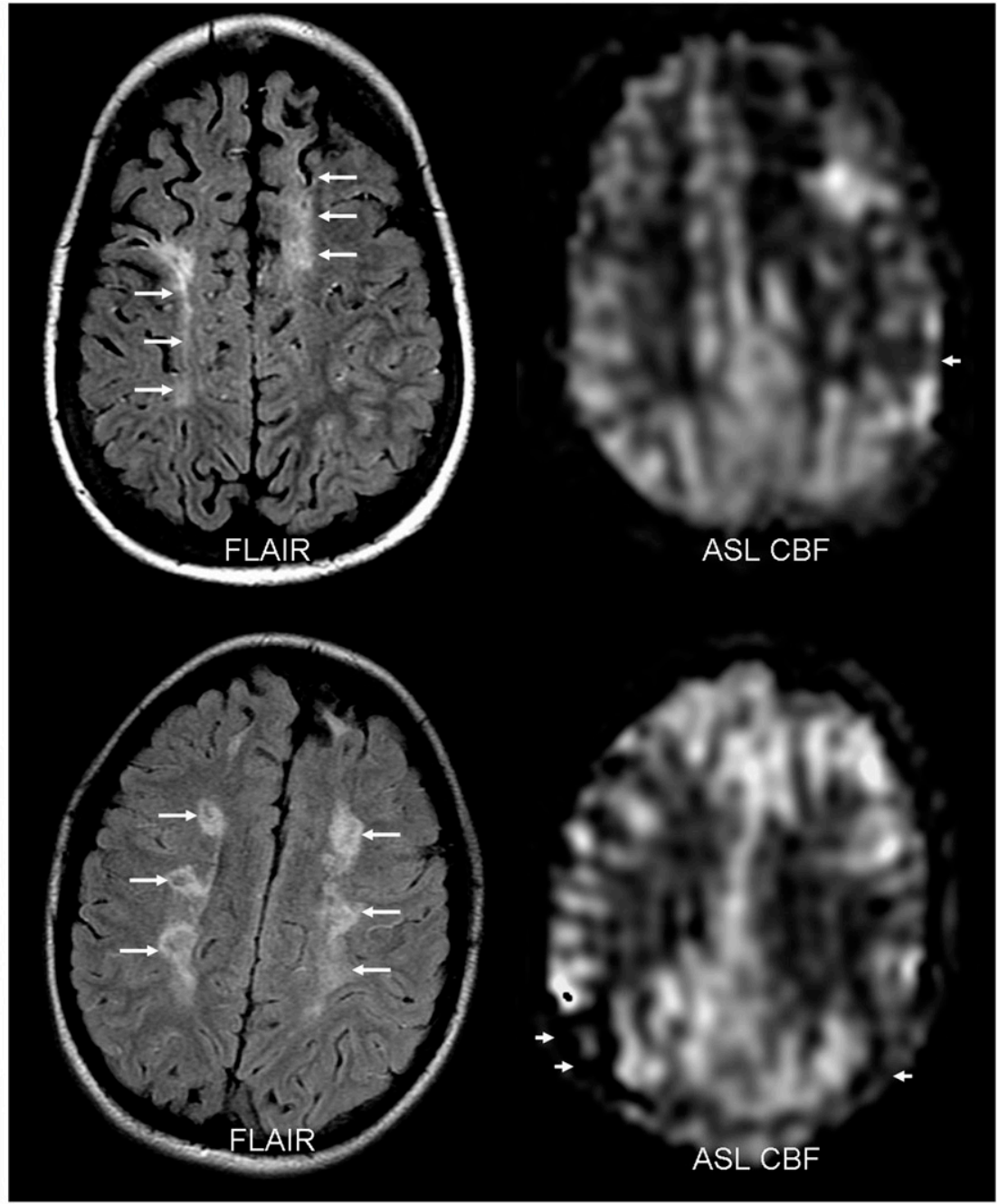

(b) penumbral zones in addition to that shown on structural MRI. ${ }^{40}$ Continuous arterial spin labelling (ASL) is a relatively new type of perfusion MRI technique, which assesses cerebral blood perfusion without the requirement for i.v. contrast administration. As such, its use may be particularly suited to children or when i.v. access cannot be achieved. ${ }^{14}$ Similar to perfusion CT, it demonstrates areas that are ischaemic or underperfused but not yet infarcted and thus may provide an estimate of the ischaemic penumbra. In one study, ASL showed matched or larger perfusion defects in patient with infarction and perfusion deficits in patients with arterial stenosis who did not have infarction (Figure 7$)^{41}$

\section{Intravenous contrast media}

The use of i.v. contrast in SCD is controversial. In vitro experiments have found increased erythrocyte aggregation in
$\mathrm{HbS}$ in the presence of iodinated contrast material correlating to dose. There is also in vitro evidence for gadolinium exacerbating erythrocyte alignment along a magnetic field, possibly increasing sickling risk. However, two recent studies found no statistically increased risk for occurrence of adverse events in patients with SCD following i.v. iodinated contrast or gadolinium, respectively. ${ }^{42,43}$

\section{CONCLUSION}

Neurological complications in SCD are common. They are usually, although not always, manifestations of the underlying vasculopathy. The main radiological patterns are those of large vessel infarction, silent infarcts and, less frequently, haemorrhage. Imaging abnormalities may be seen from early childhood sometimes requiring preventative intervention even in asymptomatic patients. 


\section{REFERENCES}

1. NHS Screening Programmes. Sickle cell disease in childhood. Standards and guidelines for clinical care 2010. 2nd edn. London, UK: NHS Sickle Cell and Thalassaemia Screening Programme; 2010.

2. Rees DC, Williams TN, Gladwin MT. Sickle-cell disease. Lancet 2010; 376: 2018-31. doi: 10.1016/S0140-6736(10) 61029-X

3. Nagel RL, Fleming AF. Genetic epidemiology of the beta s gene. Baillieres Clin Haematol 1992; 5: 331-65.

4. Lonergan G, Cline D, Abbondanzo S. Sickle cell anaemia. Radiographics 2001; 21: 971-94.

5. Moran CJ, Siegel MJ, DeBaun MR. Sickle cell disease: imaging of cerebrovascular complications. Radiology 1998; 206: 311-21. doi: 10.1148/radiology.206.2.9457180

6. Ohene-Frempong K, Weiner SJ, Sleeper LA, Miller ST, Embury S, Moohr JW, et al. Cerebrovascular accidents in sickle cell disease: rates and risk factors. Blood 1998; 91 : 288-94.

7. Steen RG, Emudianughe T, Hankins GM, Wynn LW, Wang WC, Xiong X, et al. Brain imaging findings in pediatric patients with sickle cell disease. Radiology 2003; 228: 216-25. doi: 10.1148/radiol.2281020943

8. Moser FG, Miller ST, Bello JA, Pegelow CH, Zimmerman RA, Wang WC, et al. The spectrum of brain MR abnormalities in sickle-cell disease: a report from the Cooperative Study of Sickle Cell Disease. AJNR Am J Neuroradiol 1996; 17: 965-72.

9. Armstrong FD, Thompson RJ Jr, Wang W, Zimmerman R, Pegelow $\mathrm{CH}$, Miller S, et al. Cognitive functioning and brain magnetic resonance imaging in children with sickle cell disease. Neuropsychology Committee of the Cooperative Study of Sickle Cell Disease. Pediatrics 1996; 97: 864-70.

10. Merkel KH, Ginsberg PL, Parker JC Jr, Post MJ. Cerebrovascular disease in sickle cell anemia: a clinical, pathological and radiological correlation. Stroke 1978; 9: $45-52$.

11. Mori N, Mukigura S, Higano S, Kaneta T, Fujimura M, Umetsu A, et al. The leptomengingeal "ivy sign" on fluid-attenuated inversion recovery MR imaging in Moyamoya disease: a sign of decreased cerebrovascular reserve? AJNR Am J Neuroradiol 2009; 30: 930-5.

12. Kennedy BC, McDowell MM, Yang PH, Wilson CM, Li S, Hankinson TC, et al. Pial synangiosis for moya moya syndrome in children with sickle cell anaemia: a comprehensive review of reported cases. Neurosurg Focus 2014; 36: E12. doi: 10.3171/ 2013.10.FOCUS13405

13. Adams RJ. Big strokes in small persons. Arch Neurol 2007; 64: 1567-74. doi: 10.1001/ archneur.64.11.1567

14. Deane CR, Goss D, Bartram J, Pohl KR, Height SE, Sibtain N, et al. Extracranial internal carotid arterial disease in children with sickle cell anaemia. Haematologica 2010; 95: 1287-92.

15. Kirkham FJ. Therapy insight: stroke risk and its management in patients with sickle cell disease. Nat Clin Pract Neurol 2007; 3: 264-78. doi: 10.1038/ncpneuro0495

16. Grossman R, Yousem DM. Neuroradiology: the requisites. St Louis, MO: Mosby; 2003.

17. Jordan LC, McKinstry RC 3rd, Kraut MA, Ball WS, Vendt BA, Casella JF, et al. Silent Infarct Transfusion Trial Investigators. Incidental findings on brain magnetic resonance imaging of children with sickle cell disease. Pediatrics 2010; 126: 53-61.

18. DeBaun MR, Armstrong FD, McKinstry RC, Ware RE, Vichinsky E, Kirkham FJ. Silent cerebral infarcts: a review on a prevalent and progressive cause of neurologic injury in sickle cell anemia. Blood 2012; 119: 4587-96. doi: 10.1182/blood-2011-02-272682

19. Vichinsky EP, Neumayr LD, Gold JI, Weiner MW, Rule RR, Truran D, et al. Neuropsychological Dysfunction and Neuroimaging Adult Sickle Cell Anemia Study Group. Neuropsychological dysfunction and neuroimaging abnormalities in neurologically intact adults with sickle cell anemia. JAMA 2010; 303: 1823-31.

20. Edwards CL, Raynor RD, Feliu M, McDougald C, Johnson S, Schmechel D, et al. Neuropsychological assessment, neuroimaging, and neuropsychiatric evaluation in pediatric and adult patients with sickle cell disease (SCD). Neuropsychiatr Dis Treat 2007; 3: 705-9.

21. Swift AV, Cohen MJ, Hynd GW, Wisenbaker JM, McKie KM, Makari G, et al. Neuropsychologic impairment in children with sickle cell anaemia. Paediatrics 1989; 84: 1077-85.

22. Miller ST, Macklin EA, Pegelow CH, Kinney TR, Sleeper LA, Bello JA, et al. Cooperative Study of Sickle Cell Disease. Silent infarction as a risk factor for overt stroke in children with sickle cell anemia: a report from the Cooperative Study of Sickle Cell Disease. J Pediatr 2001; 139: 385-90. doi: 10.1067/ mpd.2001.117580
23. Quinn CT, McKinstry RC, Dowling MM, Ball WS, Kraut MA, Casella JF, et al. Acute silent cerebral ischemic events in children with sickle cell anemia. JAMA Neurol 2013; 70: 58-65. doi: 10.1001/jamaneurol.2013.576

24. Pegelow CH, Wang W, Granger S, Hsu LL, Vichinsky E, Moser FG, et al. STOP Trial. Silent infarcts in children with sickle cell anemia and abnormal cerebral artery velocity. Arch Neurol 2001; 58: 2017-21.

25. Preul MC, Cendes F, Just N, Mohr G. Intracranial aneurysms and sickle cell anemia: multiplicity and propensity for the vertebrobasilar territory. Neurosurgery 1998; 42: 971-7.

26. Raj C, Killinger J, Overby P. Blood transfusion in sickle cell disease leading to posterior reversible encephalopathy syndrome (PRES). J Child Neurol 2013; 28: 1284-6. doi: 10.1177/0883073812453497

27. Khademian Z, Speller-Brown B, Nouraie SM, Minniti CP. Reversible posterior encephalopathy in children with sickle cell disease. Pediatr Blood Cancer 2009; 52: 373-5.

28. Dedeken L, Lê PQ, Azzi N, Brachet C, Heijmans C, Huybrechts S, et al. Haematopoietic stem cell transplantation for severe sickle cell disease in childhood: a single centre experience of 50 patients. $\mathrm{Br} \mathrm{J}$ Haematol 2014; 165: 402-8. doi: 10.1111/ bjh. 12737

29. Noe A, Cappelli B, Biffi A, Chiesa R, Frugnoli I, Biral E, et al. High incidence of severe cyclosporine neurotoxicity in children affected by haemoglobinopaties undergoing myeloablative hematopoietic stem cell transplantation: early diagnosis and prompt intervention ameliorated neurological outcome. Ital J Pediatr 2010; 36: 14

30. Grauer O, Wolff D, Bertz H, Greinix H, Kuehl JS, Lawitschka A, et al. Neurological manifestations of chronic graft-versus-host disease after allogeneic haematopoietic stem cell transplantation: report from the Consensus Conference on Clinical Practice in chronic graft-versus-host disease. Brain 2010; 133: 2852-65.

31. Parizel PM, Demey HE, Veeckmans G, Verstreken F, Cras P, Jorens PG, et al. Early diagnosis of cerebral fat embolism syndrome by diffusion-weighted MRI (starfield pattern). Stroke 2001; 32: 2942-4.

32. Mossa-Basha M, Izbudak I, Gurda GT, Aygun N. Cerebral fat embolism syndrome in sickle cell anaemia/ $\beta$-thalassemia: importance of susceptibility-weighted MRI. Clin Radiol 2012; 67: 1023-6. 
33. Medina FJ, Marquez JC, Castillo M. Cerebral fat embolism detection with susceptibilityweighted images in sickle cell disease.

Neuroradiol J 2012; 25: 411-14

34. Watanabe M, Saito N, Nadgir RN, Liao JH, Flower EN, Steinberg MH, et al. Craniofacial bone infarcts in sickle cell disease: clinical and radiological manifestations. J Comput Assist Tomogr 2013; 37: 91-7. doi: 10.1097/ RCT.0b013e3182752967

35. Adams R, Ohene-Frempong K, Wang W. Sickle cell and the brain. Hematology Am Soc Hematol Educ Program 2001: 31-46.

36. Adams RJ, McKie VC, Carl EM, Nichols FT, Perry R, Brock K, et al. Long-term stroke risk in children with sickle cell disease screened with transcranial Doppler. Ann Neurol 1997; 42: 699-704. doi: 10.1002/ana.410420505
37. Lee MT, Piomelli S, Granger S, Scott T, Harkness S, Brambilla DJ, et al. STOP Study Investigators. Stroke Prevention Trial in Sickle Cell Anaemia (STOP) extended follow up and final results. Blood 2006; 108: 847-52.

38. Adams RJ, Brambilla D. STOP 2 Trial Investigators. Discontinuing prophylactic transfusions to prevent stroke in sickle cell disease. N Engl J Med 2005; 335: 2769-78.

39. Buchanan ID, James-Herry A, Osunkwo I. The other side of abnormal: a case series of low transcranial Doppler velocities associated with stroke in children with sickle cell disease. J Pediatr Hematol Oncol 2013; 35: 543-6. doi: 10.1097/MPH.0b013e318279caae

40. Kirkham FJ, Calamante F, Bynevelt M, Gadian DG, Evans JP, Cox TC, et al. Perfusion magnetic resonance abnormalities in patients with sickle cell disease. Ann Neurol 2001; 49: 477-85.

41. Shellhaas RA, Silvestre DW, Wang J, Ichord RN, Licht DJ. Perfusion magnetic resonance imaging in childhood central nervous system vasculopathy and stroke. Ann Neurol 2004; 56: 92-131.

42. Campbell KL, Hud LM, Adams SA, Andrel J, Ballas SK, Feldman AM, et al. Safety of iodinated contrast medium administration in sickle cell disease. Am J Med 2012; 125: 100 e11-6.

43. Dillman JR, Ellis JH, Cohan RH, Caoili EM, Hussain HK, Campbell AD, et al. Safety of gadolinium-based contrast material in sickle cell disease. J Magn Reson Imaging 2011; 34: 917-20. doi: 10.1002/ jmri.22666 